\title{
Viral suppression in adults, adolescents and children receiving antiretroviral therapy in Cameroon: adolescents at high risk of virological failure in the era of "test and treat"
}

\author{
Joseph Fokam ${ }^{1,2,3^{*}}$ (D), Samuel Martin Sosso ${ }^{1 *}$, Bouba Yagai ${ }^{1,4}$, Serge Clotaire Billong 2,3,5, \\ Rina Estelle Djubgang Mbadie ${ }^{5}$, Rachel Kamgaing Simo ${ }^{1}$, Serge Valery Edimo ${ }^{5}$, Alex Durand Nka ${ }^{1}$, \\ Aline Tiga Ayissi', Junie Flore Yimga', Désiré Takou', Sylvie Moudourou', Marinette Ngo Nemb', \\ Jean-Bosco Nfetam Elat ${ }^{3,5}$, Maria-Mercedes Santoro ${ }^{4}$, Carlo-Federico Perno ${ }^{4,6}$, Vittorio Colizzi ${ }^{1,7,8}$ \\ and Alexis Ndjolo ${ }^{1,2}$
}

\begin{abstract}
Background: After the launching of the «Test \& Treat» strategy and the wider accessibility to viral load (VL), evaluating virological success (VS) would help in meeting the UNAIDS targets by 2020 in Cameroon.

Setting and methods: Cross-sectional study conducted in the Chantal BIYA International Reference Centre for research on HIV/AIDS prevention and management (CIRCB), Yaoundé, Cameroon; data generated between October 2016 and August 2017 amongst adults, adolescents and children at 12, 24, 36 and $\geq 48$ months on ART. VS was defined as $<1000$ copies $/ \mathrm{mL}$ of blood plasma and controlled viremia as $\mathrm{VL}<50$ copies $/ \mathrm{mL}$. Data were analysed by SPSS; $p<0.05$ considered as significant.

Results: 1946 patients (70\% female) were enrolled (1800 adults, 105 adolescents, 41 children); 1841 were on NNRTIbased and 105 on PI-based therapy; with 346 patients at M12, 270 at M24, 205 at M36 and 1125 at $\geq$ M48. The median (IQR) duration on was 48 months (24-48). Overall, VS was 79.4\% (95\% Cl 77.6-81.2) and 67.1\% (95\% Cl 64.9-69.1) had controlled viral replication. On NNRTI-based, VS was $79.9 \%$ vs. $71.4 \%$ on Pls-based, $p=0.003$. By ART duration, VS was 84.1\% (M12), 85.9\% (M24), 75.1\% (M36) and 77.2\% ( $\geq$ M48), $p=0.001$. By age, VS was $75.6 \%$ (children), $53.3 \%$ (adolescents) and $81.1 \%$ (adults), $\mathrm{p}<0.001$.
\end{abstract}

Conclusions: In this sub-population of patients receiving ART in Cameroon, about $80 \%$ might be experiencing VS, with declining performance at adolescence, with NNRTI-based regimens, and as from 36 months on ART. Thus, improving VS may require an adapted adherence support mechanism, especially for adolescents with long-term treatment in resource-limited settings.

Keywords: HIV/AIDS, Virological success, ART duration, Test and treat era, Cameroon

\footnotetext{
*Correspondence: josephfokam@gmail.com; fokamjoseph@circb.cm

${ }^{1}$ Chantal BIYA International Reference Centre for Research On HIV/ AIDS Prevention and Management (CIRCB), Melen Road, PO BOX 3077, Yaounde, Cameroon

Full list of author information is available at the end of the article
} 


\section{Introduction}

Despite many decades of continuous fight, Human immunodeficiency virus (HIV) is still one of the major global health issue, having claimed more than 35 million lives so far, with the WHO African Region in particular being the most affected with 25.7 million people living with HIV in 2017 [1, 2]. As the momentum in the efforts to control the pandemic rises, the global commitment to ending HIV/AIDS epidemic was set by the United Nations (UN) Assembly for 2030 [3]. Reducing the incidence and providing antiretroviral treatment to the infected people are key in the progress and achievement of this goal. A great stride in the journey towards ending HIV/AIDS is the ambitious treatment targets set by the Joint United Nations Programme on HIV/AIDS (UNAIDS), the $90-90-90$ strategy by 2020 . This goal stipulates that by $2020,90 \%$ of all people living with HIV will know their HIV status; $90 \%$ of all people with diagnosed HIV infection will receive sustained antiretroviral therapy; and $90 \%$ of all people receiving antiretroviral therapy will have viral suppression $[1,4]$.

Achieving these targets is especially challenging for developing countries where limited access to health care, drug availability and adequate provision of viral load monitoring tools and other programmatic issues need to be addressed. The 2017 report of the UNAIDS on ending AIDS progress reveals that globally, $70 \%$ of infected people know their HIV status, 77\% of these are receiving combination antiretroviral therapy (cART) and $82 \%$ of treated patients have virological success (VS) [4]. Studies conducted in some developing countries, such as Cameroon reported a viral suppression level less than $80 \%$ [58]. Apart from the recent Cameroon Population-based HIV impact assessment (CAMPHIA) [9], most of these studies $[6,7]$ were conducted before the implementation of the "test and treat" strategy. In addition, since most of the studies focused on adult populations $[5,9]$, data on viral suppression among children and adolescents in Cameroon are scare.

Thus, we decided to investigate on the viral suppression levels according to different age groups, therapeutic regimen and duration on ART in the "test and treat" era which is characterized by a wider accessibility to viral load testing in Cameroon.

\section{Methods}

\section{Study design and setting}

This is a retrospective cross-sectional study conducted from October 2016 to August 2017, which corresponds to the effective start of "test and treat" strategy in Cameroon. The study population was made up of children, adolescents and adults who are routinely monitored for viral load testing at the Chantal BIYA International Reference Centre for research on HIV/AIDS prevention and management (CIRCB). The CIRCB routinely receives and tests viral load (VL) samples mostly from 3 regions (the Centre, the South and the East regions of Cameroon; according to the allocation of HIV follow up units, to laboratories included in the viral load testing network by the Ministry of Public Health) out of the 10 existing regions of the country. The patients considered for this study were received from a total of 54 health facilities. However, majority of the samples were from Yaoundé, the city capital. Referring health facilities are district hospitals (349 patients), regional hospitals/central hospitals (660 patients), general hospitals (601 patients), private hospitals (271 patients) and other types of health centres (65 patients). Treatment history was collected from their medical records.

\section{Viral load quantification}

HIV-1 RNA quantification was performed on plasma samples using the Abbott m2000rt RealTime HIV-platform according to manufacturer recommendations (Abbott Molecular Inc. 1300 E. Touhy Ave. Des Plaines, IL 60018 200680-105; USA). A protocol using $0.6 \mathrm{~mL}$ of plasma was used for RNA extraction. The lower limit of detection of the assay is $<40$ copies/mL of HIV-1 RNA. This laboratory is registered with two viral load proficiency-testing programs. The study received institutional approvals from both National AIDS Control Committee (NACC) and the Chantal BIYA International Reference Centre for research on HIV/AIDS prevention and management (CIRCB).

\section{Inclusion criteria}

All patients with complete information on date of sample collection, age, date of ART start and current ART regimen; together with a VL result were included. Patients on treatment for less than 12 months were excluded from our analysis. Data were queried from the data base and was cleaned. Age groups were defined as follows: children ( $0-9$ years), adolescents (10-19 years) and adults $\geq 20$ years. Virological success (VS) was defined as viral load $(\mathrm{VL})<1000$ RNA-copies/mL of blood plasma, virological failure (VF) as $\mathrm{VL} \geq 1000$ RNA-copies/mL [10] and very low level viremia $<50$ copies/mL [11] was considered as controlled viremia.

\section{Data analysis}

All data were analysed using SPSS version 20.0 (SPSS Inc., Chicago, Illinois), with a statistical significance level set at $\mathrm{p}<0.05$. Frequencies, proportions, confidence interval were computed and data were summarised using tables and figures. Hypothesis testing was performed 
using Pearson Chi Square and Chi Square for trends as appropriate.

\section{Results}

\section{Participants' characteristics}

Table 1 shows the characteristics of our study population. A total of 1946 patients were enrolled, all reported to be naïve to cART at the moment of treatment initiation. The majority was female (1373; 71\%) were enrolled in this study. The median (interquartile range: IQR) age of our study sample was 41 years (IQR: $34-50$ years); the median year of cART start was 2012 (IQR: 2009-2014); and the median duration on treatment was 48 months (IQR: 24-48 months). Most patients were adults
(92.5\%) and $89.3 \%$ lived in an urban area. Among the 1841 patients on first line antiretroviral therapy, most patients 1017 were on tenofovir + lamivudine + efavirenz (TDF $+3 \mathrm{TC}+\mathrm{EFV})$ combination. Out of the 1946 patients, $49.7 \%$ was diagnosed following a consultation, against $28.2 \%$ in voluntary screening and $15.3 \%$ of females during PMTCT (protection of HIV transmission from mother to child program).

\section{Prevalence of viral suppression}

The overall prevalence of VS after at least 12 months on cART at $\mathrm{VS}<1000$ copies/mL and $\mathrm{VS}<50$ copies/ $\mathrm{mL}$ was $79.4 \%$ (95\% Confidence interval, CI 77.6-81.2) and $67.1 \%$ (95\% CI 64.9-69.1) respectively. The median

Table 1 Population characteristics and viral suppression levels

\begin{tabular}{|c|c|c|c|c|c|}
\hline Variable & $\begin{array}{l}\text { Overall }^{\mathrm{a}} \\
\mathrm{N}=1946\end{array}$ & $\begin{array}{l}<50 \text { copies } / \mathrm{mL}^{\mathrm{b}} \\
\mathrm{N}=1305(67.1 \%)\end{array}$ & $\begin{array}{l}<1000 \text { copies } / \mathrm{mL}^{b} \\
\mathrm{~N}=1546(79.4 \%)\end{array}$ & $\begin{array}{l}\geq 1000 \text { copies } / \mathrm{mL}^{b} \\
\mathrm{~N}=400(20.6 \%)\end{array}$ & p-value* \\
\hline Age in year, median (IQR) & $41(34-50)$ & $41(34-50)$ & $42(34-50)$ & $39(33-49)$ & $<0.001$ \\
\hline Year of cART start, median (IQR) & $2012(2009-2014)$ & $2012(2009-2014)$ & $2012(2009-2014)$ & $2011(2008-2013)$ & $<0.001$ \\
\hline Duration on CART in month, median (IQR) & $48(24-48)$ & $48(24-48)$ & $48(24-48)$ & $48(36-48)$ & 0.001 \\
\hline \multicolumn{6}{|l|}{ Gender, n (\%) } \\
\hline Male & $573(29.4)$ & $352(61.4)$ & $435(75.9)$ & $138(24.1)$ & \multirow[t]{2}{*}{0.013} \\
\hline Female & $1373(70.6)$ & $953(69.4)$ & $1111(80.9)$ & $262(19.1)$ & \\
\hline \multicolumn{6}{|l|}{ Age groups, n (\%) } \\
\hline Children & $41(2.1)$ & $25(61.0)$ & $31(75.6)$ & $10(24.4)$ & \multirow{3}{*}{$<0.001$} \\
\hline Adolescents & $105(5.4)$ & $46(43.8)$ & $56(53.3)$ & $49(46.7)$ & \\
\hline Adults & $1800(92.5)$ & $1234(68.6)$ & $1459(81.1)$ & $341(18.9)$ & \\
\hline \multicolumn{6}{|l|}{ Therapeutic regimen, n (\%) } \\
\hline First line & $1841(94.6)$ & $1261(68.5)$ & $1471(79.9)$ & $370(20.1)$ & \multirow[t]{2}{*}{0.037} \\
\hline Second line & $105(5.4)$ & $44(41.9)$ & $75(71.4)$ & $30(28.6)$ & \\
\hline \multicolumn{6}{|l|}{ ARV combination, n (\%) } \\
\hline$T D F+3 T C+E F V$ & $1070(55.0)$ & $770(72.0)$ & $890(83.2)$ & $180(16.8)$ & \multirow[t]{3}{*}{$<0.001$} \\
\hline Other 1st line ARV & $771(39.6)$ & $491(63.7)$ & $581(75.4)$ & $190(24.6)$ & \\
\hline ATVr or LPVr Based ARV ${ }^{d}$ & $105(5.4)$ & $44(41.9)$ & $75(71.4)$ & $30(28.6)$ & \\
\hline \multicolumn{6}{|l|}{ Circumstance of diagnosis, n (\%) } \\
\hline Consultation & $967(49.7)$ & $625(64.6)$ & $750(77.6)$ & $217(22.4)$ & \multirow[t]{5}{*}{$<0.001$} \\
\hline Voluntary & $549(28.2)$ & $396(72.1)$ & $461(84.0)$ & $88(16.0)$ & \\
\hline РMTCT & $210(10.8)$ & $153(72.9)$ & $180(85.7)$ & $30(14.3)$ & \\
\hline At birth & $41(2.1)$ & $22(53.7)$ & 25 (61.0) & $16(39.0)$ & \\
\hline Other/unknown & $179(9.2)$ & 109 (60.9) & $130(72.6)$ & 49 (27.4) & \\
\hline \multicolumn{6}{|l|}{ Urban vs rural, n (\%) } \\
\hline Urban & 1737 (89.3) & 1171 (67.4) & 1388 (79.9) & $349(20.1)$ & \multirow[t]{3}{*}{0.004} \\
\hline Rural & $144(7.4)$ & $98(68.1)$ & $117(81.2)$ & 27 (18.8) & \\
\hline Unknown & 65 (3.3) & $36(55.4)$ & $41(63.1)$ & $24(36.9)$ & \\
\hline
\end{tabular}

CART combined antiretroviral therapy, ARV antiretroviral, TDF tenofovir, 3TC lamivudine, EFV efavirenz, ATVr ritonavir boosted atazanavir, LPVr ritonavir boosted lopinavir, PMTCT prevention from mother to child transmission, IQR interquartile range

a Percentages in this column represent column percentage

b Percentages in this column represents row percentage

c Other first line ARV $[3 T C+d 4 T+\operatorname{NVP}(n=1), A B C+3 T C+E F V(n=12), A B C+3 T C+N V P(n=5), A Z T+3 T C+E F V(n=51), A Z T+3 T C+E F V(n=486)$, TDF $+3 T C+N V P(n=216)$

d Lopinavir based $(n=31)$ and atazanavir based $(n=68)$. $p$-value for virological success at $<1000$ copies $/ \mathrm{mL}$ 


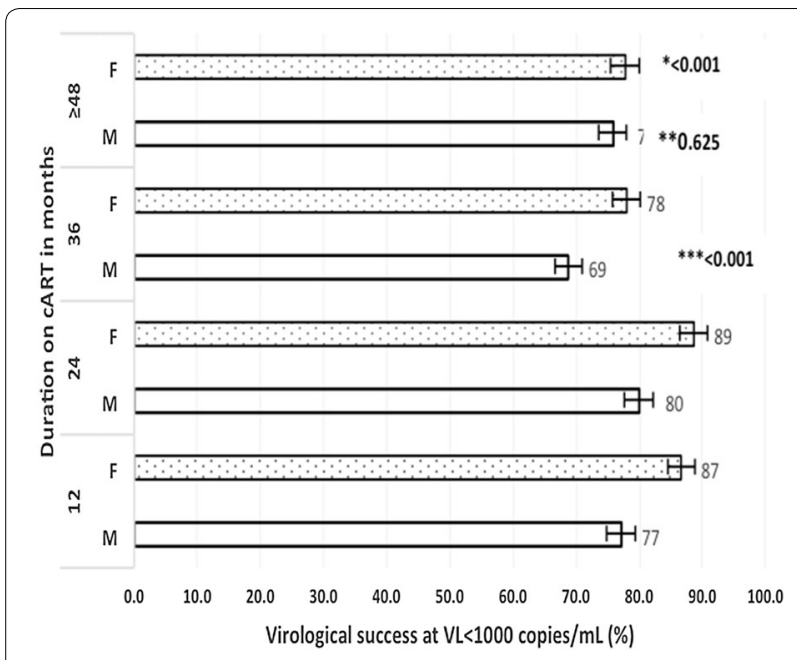

Fig. 1 On-treatment virological success per duration on CART and per gender. CART combination antiretroviral therapy, VL viral load, $F$ female, $M$ male. ${ }^{*} p$-value for trend of virological success per duration on cART and per female gender; ${ }^{* *} p$-value for trend of virological success per duration on CART and per male gender; ${ }^{* * *}$ overall p-value for trend of total population. Error bars represent 95\% confidence interval

age, median year of cART initiation, and median duration on CART for patients failing treatment vs. those on VS at $\geq 12$ months of cART were: 39 [IQR: 33-49] years vs. 41 [IQR: 34-50] years, $\mathrm{p}<0.001$; calendar year 2011 [IQR: 2008-2013] vs. calendar year 2012 [IQR: 20092014], p < 0.001; and 48 [IQR: 36-48] months vs. 48 [IQR: 24-48] months, $\mathrm{p}=0.001$; respectively.

According to ART duration, VS was $84.1 \%$ at 12 months (M12), 85.9\% at 24 months (M24), $75.1 \%$ at 36 months (M36) and 77.2\% at more 48 months ( $\geq$ M48), $\mathrm{p}=0.001$. The overall VS was $75.9 \%$ (95\% CI 72.3-79.2) for males and $80.9 \%$ (95\% CI 78.8-82.9) for females, $\mathrm{p}=0.013$; while overall controlled viremia was $61.4 \%$ for male and $69.4 \%$ for female $(p=0.001)$. There was a large variation of VS prevalence with respect to age groups for both VS thresholds $(\mathrm{p}<0.001)$; with the highest prevalence of virological failure at VS $\geq 1000$ copies/ $\mathrm{mL}$ being recorded among adolescents (46.7\%), followed by children $(24.4 \%)$. When compared according to cART regimens, $\mathrm{TDF}+3 \mathrm{TC}+\mathrm{EFV}$, others first line combinations, and ritonavir-boosted lopinavir (LPV/r)/atazanavir $(\mathrm{ATV} / \mathrm{r}$ )-based ARV) at $\mathrm{VS}<1000$ copies/mL, patients on $\mathrm{TDF}+3 \mathrm{TC}+\mathrm{EFV}$ recorded the highest VS (83.2\%) versus $71.4 \%$ on $\mathrm{PI} / \mathrm{r}$-based regimens, $\mathrm{p}<0.001$.

According to circumstances of HIV diagnosis, at both $\mathrm{VS}<50$ copies/mL and VS $<1000$ copies/mL, those diagnosed during PMTCT had the highest prevalence $(72.9 \%$ and $85.7 \%$ respectively), followed by patients screened voluntarily (72.1\% and $84.0 \%$ respectively); with patients

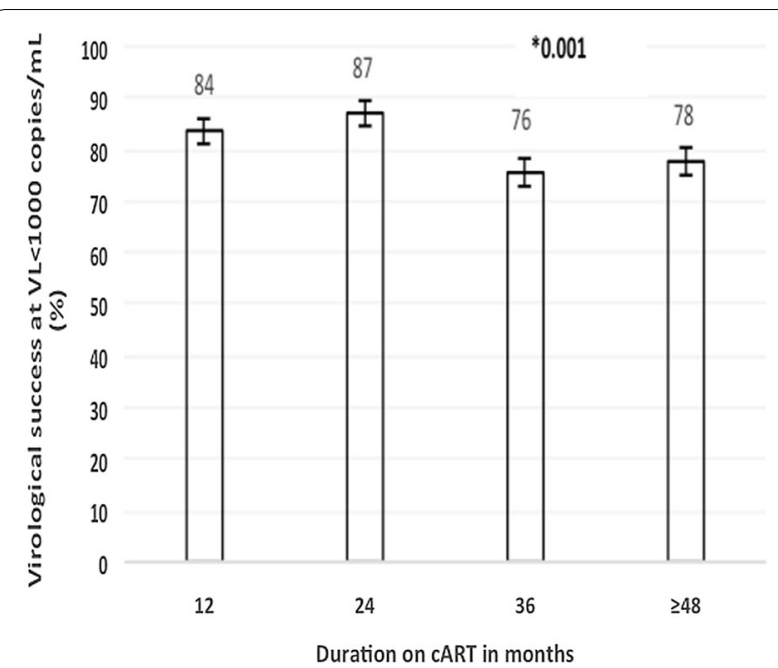

Fig. 2 On-treatment virological success per duration on 1st line-NNRTI-based CART. CART combination antiretroviral therapy, VL viral load, 1st line first line therapy-NNRTI-based. * $\mathrm{p}$-value for trend of the 1 st line over time. Error bars represent the 95\% confidence interval

diagnosed at birth recording the worst performance (53.7\% and $61.0 \%$ respectively); $\mathrm{p}<0.001$. Figure 1 shows that for $\mathrm{VS}<1000$ copies/mL per duration on cART and per gender, the prevalence ranged from $69 \%$ to $80 \%$ (at 36 and 24 months respectively) for male $(\mathrm{p}=0.625)$; against $78 \%$ to $89 \%$ ( $\geq 36$ months and 24 months respectively) for female $(\mathrm{p}<0.001)$. On the other hand, Fig. 2 shows that for the same VS level per duration on cART and per 1st line NNRTI (non-nucleoside reverse transcriptase inhibitor)-based therapy, it ranged from $76 \%$ to $87 \%$ (at M36 and M24 respectively), $\mathrm{p}=0.001$ ).

\section{Discussion}

In this study, we aimed at estimating the prevalence of virological success per age groups, duration on cART and therapeutic line among HIV/AIDS patients in Cameroon. It shows that at the start of the "test and treat" era in Cameroon, the overall prevalence of VS $<1000$ copies/ $\mathrm{mL}$ after at least 12 months of cART was $79.4 \%$ (95\% CI 77.6-81.2); about $11 \%$ away from the $90 \%$ target set by UNAIDS by 2020 . This performance is less than the $82 \%$ reported global VS performance [4]. In the other hand, the prevalence of patients with controlled viremia after at least 12 months of cART was $67.1 \%$ (95\% CI 64.969.1), far away from the high VS reported in many western countries [12]. The virological failure rate of $20.6 \%$ observed in this study was within the range reported in other developing countries, which is $3.7 \%$ to $26.0 \%$ [7]. Previous studies in Cameroon reported VS between 72.1 and $90.2 \%[5,6,9,13]$, with the differences in VS 
performance mostly attributed to differences in study population characteristics and duration on cART. Our result is closely similar to the recent and country wide population based HIV impact assessment (CAMPHIA) study which found $80 \%$ VS. The high VF in this study may be either related to the fact that many patients might be treatment failure suspects and/or repeat testers after suspect failure, which are known to record a high VF compared to patients on routine monitoring [14]; or to a relatively higher proportion of children and adolescents (compared to other studies in Cameroon), who generally have a low response $[9,14-19]$, especially in settings with a weak health system.

The median age (IQR) of virally suppressed patients was 42 years ( $34-50$ years) versus 39 years (33-49 years) in treatment failure patients $(\mathrm{p}<0.001)$. In fact, our result shows that children $(<10$ years) and/or adolescents $(10-$ 19 years) are much less likely to achieve virological success compared to adult populations $(\mathrm{p}<0.001)$. Poor ART response of HIV-infected children (especially infants perinatally infected) compared to adult populations is well documented. This could be justified by the higher viral replication and the less efficient immune response against infections in infants [20-22]. Moreover, patients with pre-therapy viral load of $>500,000$ copies/mL (commonly observed in children) are known to have longer time to VS and a higher probability of virological rebound after VS [23]. Nonetheless, suboptimal adherence level is also a major challenge often reported in children [24].

The lack of adherence and adequate provision of psychological supports in children and adolescents has been reported to represent the major cause of loss to followup and virological failure [14, 24]. The VS performance observed in our study in adolescent population in particular is a call for concern. It was also recognized in some settings that they have a limited access to antiretrovirals (ARVs) [3]. Thus, there is a need to give a special considerations to these vulnerable groups in the provision of health care delivery. In addition, they should have more access to drug resistance testing because they have been reported to record generally a high burden of HIV drug resistance $[25,26]$.

According to gender, females are more likely to experience virological success than men $80.9 \%$ vs $75.9 \%$ respectively, $\mathrm{p}=0.013)$. Even though the recent CAMPHIA study reported a relatively higher VS in men than women $(80.1 \%$ vs $79.2 \%)$ [9], data from many studies suggest that men are likely to experience virological failure than females $[4,15]$. This can be justified by their high risk related behavioural patterns. For example, studies reported that the masculine gender norms contribute to greater risk-taking; expressing manhood by having multiple sex partners, refusal to use condoms, alcohol and substances abuse; and poorer uptake of health services [27-30]; all leading to a poorer adherence and treatment interruption which favour treatment failure. In addition, it is recognised especially in some Sub-Saharan Africa that men are most likely to die of HIV/AIDS than women $[27,30]$ because they have lower knowledge of HIV/AIDS [16], and present generally to health service latter with advanced disease conditions [30-32]. While sustaining and improving the access to ARV and VS in women through existing programs, men should not be left behind. Since current health system design may be responsible for these gaps, designing interventions separately for males and females, filling the gaps in the continuum of HIV/AIDS care [33] and increasing case finding through PMTCT, index and work place testing $[4,28,30]$ may help achieve the $90 \%$ target UNAIDS goal.

The treatment failure rate at $\mathrm{VS}<1000$ copies/ $\mathrm{mL}$ was higher among patients on second line compared to first line patients ( $28.6 \%$ vs $20.1 \%$ respectively, $\mathrm{p}=0.037)$. When compared according to ARV combinations (TDF + 3TC +EFV, others first line combinations or protease inhibitors-based ARV, patients on $\mathrm{TDF}+3 \mathrm{TC}+\mathrm{EFV}$ recorded the highest virological success $(83.2 \%)$ versus $75.4 \%$ and $71.4 \%$ for other first line and PI-based regimen respectively $(\mathrm{p}<0.001)$. Most studies reported more than $80 \%$ VS in patients on PI based therapy [34-36]. Even though low rate of switching from first to second line, which may affect second line response is sometimes reported [37], Protease inhibitors (PIs) based regimens are generally protective against VF [19]. The small number of patients (105) on second line in our study may not be representative; however, this may indicate adherence challenges among patients in second line treatment. Our result also suggests that there is a better response to TDF $+3 \mathrm{TC}+\mathrm{EFV}$ combination compared to other first line options (including those that are nevirapine (NVP)-based and those containing zidovudine (AZT), stavudine (d4T) and abacavir (ABC) as NRTIbackbone). In fact, this combination has been found to be equivalent or superior to its comparator arms (other nucleoside reverse transcriptase (NRTI) - backbone and/ or NNRTI) in many studies [38-41].

According to duration on therapy, VF was associated with longer stay on cART (median year of cART start: 2011 (2008-2013) versus 2012 (2009-2014 for VF and VS group respectively, $\mathrm{p}<0.001)$. Similar trend was equally reported after 6 months and 48 months on cART in a review [8]. The individual increase in the lack of tolerability and the emergence of multi strain viruses with time greatly account for this reduced VS $[6,14,42,43]$. A study in Cameroon reported that the prevalence of VF and resistance increased with time on ART, from 12.0 to $8.0 \%$ in the 6 - to 12 -month group to $31.3 \%$ and $27.1 \%$ in 
the $>72$-month group, respectively [5]. Unavailability of ART at the treatment centre was reported as the single most common cause for incomplete adherence in rural Cameroon [44]; strategies to improve adherence through health system strengthening should be implemented. To limit the emergence of viral resistance and achieved a higher and sustained VS, the use of novel drug classes such integrase strand transfer inhibitors (INSTI) class in first line, which has a demonstrated excellent efficacy and resistance profile in clinical practice, and recommended by many guidelines today will be a good option [43, 4548]. Figure 1 suggests that the variation of VS over time in females showed a significant level $(\mathrm{p}<0.001)$, while variation in males was not significant $(p=0.625)$. Gender differences in HIV disease progression and treatment outcomes among females and males [49] as well as other socio cultural characteristics, behavioural differences and disease perception may account for such differences.

According to reasons/circumstances of diagnosis, the VS varied significantly among the patients $(\mathrm{p}<0.001)$. The VF among patients diagnosed during consultation was $22.4 \%$, against $16.0 \%$ in patients who undertook voluntarily testing and $14.3 \%$ in women diagnosed during PMTCT. Additional data should be collected to better understand how engaging potentially infected persons and key populations in voluntary screening may contribute in achieving also the third "90". Contrary to other studies, we noted a higher VS among patients from Rural area compared to those in urban area $(\mathrm{p}=0.004)$. The major limitation of this study is that data were not collected on whether VL was requested for routine monitoring, suspects failure or repeat testers after failure, and might have confounded our estimates. Additionally, even though the acquired HIV drug resistance among patients failing ART is still of concern in Cameroon, we could not present these data in our study because they were not performed. We therefore recommend subsequent studies to investigate other predictors to VF and acquired HIV drug resistance profile among patients failing ART in such setting.

\section{Conclusion}

In this sub-population of patients receiving ART in Cameroon, about 8 out of 10 might be experiencing VS (with a gap of $10 \%$ below the required target set by 2020), with poorer outcomes among adolescents and those as from 36 months on cART. Furthermore, VS appears higher in females and in those treated with TDF + 3TC + EFV compared to other NNRTI-based or $\mathrm{PI} / \mathrm{r}$-based regimens. Thus, strategies towards improved monitoring of adolescents, male and long-term treated patients are crucial in maximising VS, while access to timely switch of ART and/or drug resistance would help in alleviating the burden VF and in meeting the target for ART response in RLS.

\section{Acknowledgements}

We thank Ondingui Juliette, Ninsu Cedric, Zoufack Dacein, Weladji Richid, and Charlotte Tangipundu who contributed in data collection and testing.

\section{Authors' contributions}

Designed the study: JF, SMS, BY, REDM, SCB; Collected the data: SMS, BY, JF, ADN, ATA, JFY, DT, SM, RKS; Analysed and interpreted the data: JF, BY, SMS, SCB, MNN, J-BNE, M-MS, C-FP, VC, AN. Initiated the manuscript: drafted the manuscript: JF, SMS, BY; Revised the manuscript. All the authors read and approved the final manuscript.

\section{Funding}

This work was supported by the "Chantal Biya" International Reference Centre for research on HIV/AIDS prevention and management (CIRCB), under the Annual Budget 2016-2018. The study was partly supported by EDCTP2, the European and Developing Countries Clinical Trial Partnership, CDF-TMA 1027, by facilitating the relocation of the principal investigator (Dr. Joseph FOKAM) for research at the home institution.

Availability of data and materials

Data supporting the findings are fully available in the results, in the tables and figures of the manuscript.

\section{Ethics approval and consent to participate}

This study was institutionally approved by the Chantal Biya International Reference Center (CIRCB) for research on HIV/AIDS prevention and management in Cameroon. As per the retrospective design, informed consent was not required, following institutional appraisal. Data were collected from the laboratory records with respect of confidentiality using di-identified numbers.

Consent for publication

Not applicable.

Competing interests

The authors declare that they have no competing interests.

\section{Author details}

${ }^{1}$ Chantal BIYA International Reference Centre for Research On HIV/AIDS Prevention and Management (CIRCB), Melen Road, PO BOX 3077, Yaounde, Cameroon. ${ }^{2}$ Faculty of Medicine and Biomedical Sciences, University of Yaoundé I, Yaoundé, Cameroon. ${ }^{3}$ National HIV Drug Resistance Working Group, Ministry of Public Health, Yaounde, Republic of Cameroon. ${ }^{4}$ Department of Experimental Medicine, Faculty of Medicine and Surgery, University of Rome Tor Vergata, Rome, Italy. ${ }^{5}$ Central Technical Group, National AIDS Control Committee, Yaoundé, Cameroon. ${ }^{6}$ Department of Microbiology, University of Milan, Milan, Italy. ${ }^{7}$ UNESCO Multidisciplinary Board of Biotechnology, University of Rome Tor Vergata, Rome, Italy. ${ }^{8}$ Faculty of Biomedical Sciences, Evangelic University of Cameroon, Bandjoun, Cameroon.

Received: 3 July 2019 Accepted: 9 November 2019

Published online: 19 November 2019

\section{References}

1. Joint United Nations Programme on HIV/AIDS (UNAIDS). 90-90-90: an ambitious treatment target to help end the AIDS epidemics. http:// www.unaids.org/sites/default/files/media_asset/90-90-90_en.pdf. Accessed Oct 2014.

2. World Health Organization (WHO). HIV/AIDS key facts. http://www. who.int/news-room/fact-sheets/detail/hiv-aids; Accessed 19 July 2018.

3. United Nations (UN). Political declaration on HIV and aids: on the fast track to accelerating the fight against HIV and to ending the AIDS epidemic by 2030. http://www.unaids.org/sites/default/files/media_asset /2016-political-declaration-HIV-AIDS_en.pdf. Accessed June $201 \overline{6}$. 
4. Joint United Nations Programme on HIV/AIDS (UNAIDS). Ending AIDS Progress towards the 90-90-90 targets. http://www.unaids.org/sites/ default/files/media_asset/Global_AIDS_update_2017_en.pdf. 2017.

5. Boullé $C$, Guichet E, Kouanfack $C$, et al. Virologic failure and human immunodeficiency virus drug resistance in rural Cameroon with regard to the UNAIDS 90-90-90 treatment targets. Open Forum Infect Dis. 2016;3(4):ofw233.

6. Tchouwa GF, Eymard-Duvernay S, Cournil A, et al. Nationwide estimates of viral load suppression and acquired HIV drug resistance in Cameroon. EClinicalMedicine. 2018;1:21-7.

7. Aghokeng AF, Monleau M, Eymard-Duvernay S, et al. Extraordinary heterogeneity of virological outcomes in patients receiving highly antiretroviral therapy and monitored with the world health organization public health approach in sub-Saharan Africa and southeast Asia. Clin Infect Dis. 2014;58(1):99-109.

8. Boender TS, Sigaloff KCE, McMahon JH, et al. Long-term virological outcomes of first-line antiretroviral therapy for HIV-1 in Low- and MiddleIncome Countries: a systematic review and meta-analysis. Clin Infect Dis. 2015;61(9):1453-61.

9. International Centre for AIDS prevention (ICAP). Cameroon Populationbased HIV Impact Assessment (CAMPHIA) 2017: preliminary findings. https://phia.icap.columbia.edu/wpcontent/uploads/2018/07/3471C AMPHIA_Cameroon-SS_A4_v13_requests_7.25.18.pdf. Accessed July 2018.

10. Taieb F, Madec Y, Cournil A, et al. Virological success after 12 and 24 months of antiretroviral therapy in Sub-Saharan Africa: comparing results of trials, cohorts and cross-sectional studies using a systematic review and meta-analysis. PLOS ONE. 2017;12(4):e0174767.

11. Sarmati L, D'ettorre G, Parisi SG, et al. HIV Replication at Low Copy Number and its correlation with the HIV reservoir: a clinical perspective. Curr HIV Res. 2015:13:250-7.

12. European Centre for Disease Prevention and Control (ECDC). Strategies to reduce HIV incidence in Europe. J Int AIDS Soc. 2018;21(Suppl. 8):e25187.

13. Billong SC, Fokam J, Aghokeng AF, et al. Population-based monitoring of emerging HIV-1 drug resistance on antiretroviral therapy and associated factors in a sentinel site in Cameroon: low levels of resistance but poor programmatic performance. PLoS ONE. 2013;8(8):1-6.

14. Bulage L, Ssewanyana I, Nankabirwa V, et al. Factors associated with virological non-suppression among HIV-positive patients on antiretroviral therapy in Uganda, August 2014-July 2015. BMC Infect Dis. 2017;17(1):1-11.

15. Novitsky V, Gaolathe T, Mmalane M, et al. Lack of virological suppression among young HIV-positive adults in Botswana. J Acquir Immune Defic Syndr. 2018;78(5):557-65.

16. Agolory $\mathrm{S}$, Klerk M, et al. Low case finding among men and poor viral load suppression among adolescents are impeding Namibia's ability to achieve UNAIDS 90-90-90 targets. Open Forum Infect Dis. 2018;5(9):200.

17. Parienti J-J, Massari V, Descamps D, et al. Predictors of virologic failure and resistance in HIV-infected patients treated with nevirapine- or efavirenzbased antiretroviral therapy. Clin Infect Dis. 2004;38(9):1311-6.

18. Sithole Z, Mbizvo E, Chonzi P, et al. Virological failure among adolescents on ART, Harare City, 2017-a case-control study. BMC Infect Dis. 2018;18(1):469.

19. Mujugira A, Celum C, Tappero JW, et al. Younger age predicts failure to achieve viral suppression and virologic rebound among HIV-1-infected persons in serodiscordant partnerships. AIDS Res Hum Retroviruses. 2016;32(2):148-54.

20. Ásbjörnsdóttir KH, Hughes JP, Wamalwa D, et al. Differences in virologic and immunologic response to antiretroviral therapy among HIV-1-infected infants and children. AIDS. 2016;30(18):2835-43.

21. Shearer WT, Quinn TC, larussa P, et al. Viral load and disease progression in infants infected with human immunodeficiency virus type 1. N Engl J Med. 1997;336(19):1337-42.

22. Richardson BA, Mbori-Ngacha D, Lavreys $L$, et al. Comparison of human immunodeficiency virus type 1 viral loads in Kenyan women, men, and infants during primary and early infection. J Virol. 2003;77(12):7120-3.

23. Santoro MM, Alteri C, Flandre P, et al. Impact of pre-therapy viral load on virological response to modern first-line HAART. Antivir Ther. 2013;18(7):867-76.

24. International AIDS Socicety (IAS). Research for an AIDS free generation: A global research agenda for adolescents living with HIV. https://www.
iasociety.org/Web/WebContent/File/CIPHER_policy_brief_ado_EN.pdf. Accessed July 2017

25. Ong DSY, Frencken JF, Klouwenberg PMCK, et al. HIV drug resistance in African infants and young children newly diagnosed with HIV: a multicounty analysis. Infect Dis Soc Am. 2017;65(12):2018-25.

26. Owusu M, Mensah E, Enimil A, et al. Prevalence and risk factors of virological failure among children on antiretroviral therapy. BMJ Glob Heal. 2017;2(Suppl. 2):A1-67.

27. Cornell M, Mclntyre J, Myer L. Men and antiretroviral therapy in Africa: our blind spot. Trop Med Int Health. 2011;16(7):828-9.

28. Ochieng-Ooko V, Ochieng D, Sidle JE, et al. Influence of gender on loss to follow-up in a large HIV treatment programme in Western Kenya. Bull World Health Organ. 2010;88(9):681-8.

29. Kranzer K, Lewis JJ, Ford N, et al. Treatment interruption in a primary care antiretroviral therapy program in South Africa: cohort analysis of trends and risk factors. J Acquir Immune Defic Syndr. 2010;55(3):e17-23.

30. Taylor-Smith K, Tweya H, Harries A, et al. Gender differences in retention and survival on antiretroviral therapy of HIV-1 infected adults in Malawi. Malawi Med J. 2010;22(2):49-56.

31. Cornell M, Grimsrud A, Fairall L, et al. Temporal changes in programme outcomes among adult patients initiating antiretroviral therapy across South Africa, 2002-2007. J Acquir Immune Defic Syndr. 2010;24(14):2263-70

32. Schneider H, Govender V, Harris B, et al. Gender differences in experiences of ART services in South Africa: a mixed methods study. Trop Med Int Health. 2012;17(7):820-6.

33. Alvarez-uria G, Pakam R, Midde M, et al. Entry, retention, and virological suppression in an HIV cohort study in India, description of the cascade of care and implications for reducing HIV-related mortality in Low- and Middle-Income Countries. Interdiscip Perspect Infect Dis. 2013;2013:1-9.

34. Collier D, Iwuji C, Derache A, et al. Virological outcomes of second-line protease inhibitor-based treatment for human immunodeficiency virus type 1 in a high-prevalence rural South African setting: a competing-risks prospective cohort analysis. Clin Infect Dis. 2017;64(8):1006-16.

35. Ségéral $\mathrm{O}$, Nerrienet $\mathrm{E}$, Neth $\mathrm{S}$, et al. Positive virological outcomes of HIV-infected patients on Protease Inhibitor-based second-line regimen in Cambodia: the ANRS 12276 2PICAM Study. Front Public Heal. 2018;6:63.

36. Hosseinipour MC, Gupta RK, Van Zyl G, et al. Emergence of HIV drug resistance during first- and second-line antiretroviral therapy in resourcelimited settings. J Infect Dis. 2013;207(Suppl. 2):49-56.

37. Kyaw NTT, Harries AD, Kumar AMV, et al. High rate of virological failure and low rate of switching to second-line treatment among adolescents and adults living with HIV on first line ART in Myanmar, 2005-2015. PLoS ONE. 2017;12(2):e0171780.

38. Nachega JB, Hislop M, Dowdy DW, et al. Efavirenz versus nevirapinebased initial treatment of HIV infection: clinical and virological outcomes in Southern African adults. J Acquir Immune Defic Syndr. 2008;22(16):2117-25.

39. Philip K, Naiel N, Clinton W, et al. Comparison of nevirapine- and efavirenz-containing antiretroviral regimens in antiretroviral-naïve patients: a cohort study. HIV Clin Trials. 2002;3(4):296-303.

40. Matthews GV, Sabin CA, Mandalia S, et al. Virological suppression at 6 months is related to choice of initial regimen in antiretroviral-naive patients: a cohort study. J Acquir Immune Defic Syndr. 2002;16(1):53-61.

41. Tang MW, Kanki PJ, Shafer RW. A review of the virological efficacy of the 4 World Health Organization-recommended tenofovir-containing regimens for initial HIV therapy. Clin Infect Dis. 2012;54(6):862-75.

42. Mekuria LA, Nieuwkerk PT, Yalew AW, et al. High level of virological suppression among HIV infected adults receiving combination antiretroviral therapy in Addis Ababa, Ethiopia. Antivir Ther. 2016;21(5):385-96.

43. Cihlar T, Fordyce M. Current status and prospects of HIV treatment. Curr Opin Virol. 2016;18:50-6.

44. Zoufaly A, Jochum J, Hammerl R, et al. Virological failure after 1 year of first-line ART is not associated with HIV minority drug resistance in rural Cameroon. J Antimicrob Chemother. 2015;70(3):922-5.

45. Peñafiel J, de Lazzari E, Padilla $M$, et al. Tolerability of integrase inhibitors in a real-life setting. J Antimicrob Chemother. 2017;72(6):1752-9.

46. Wong E, Trustman N, Yalong A. HIV pharmacotherapy. J Am Acad Physician Assist. 2016;29(2):36-40.

47. European AIDS Clinical Society (EACS). Guideline Version 9.1. http://www. eacsociety.org/files/2018_guidelines-9.1-english.pdf. Accessed Oct 2018. 
48. AIDSinfo. Guidelines for the use of antiretroviral agents in adults and adolescents living with HIV. https://aidsinfo.nih.gov/contentfiles/lvgui delines/adultandadolescentgl.pdf. Accessed Oct 2018.

49. Mosha F, Muchunguzi V, Matee M, et al. Gender differences in HIV disease progression and treatment outcomes among HIV patients one year after starting antiretroviral treatment (ART) in Dar es Salaam, Tanzania. BMC Public Health. 2013:13:38.

\section{Publisher's Note}

Springer Nature remains neutral with regard to jurisdictional claims in published maps and institutional affiliations.
Ready to submit your research? Choose BMC and benefit from:

- fast, convenient online submission

- thorough peer review by experienced researchers in your field

- rapid publication on acceptance

- support for research data, including large and complex data types

- gold Open Access which fosters wider collaboration and increased citations

- maximum visibility for your research: over 100M website views per year

At BMC, research is always in progress.

Learn more biomedcentral.com/submissions 